complained that no attempt had been made to define arthritis deformans.

The President of the Section (Dr. Stephen Mackenzie) thought they had had an interesting and valuable debate and the great diversity of views expressed showed how far they were from finality on the subject. He thought it probable that several different states were included under the term arthritis deformans. He referred to the opinion of the late Dr. Sutton, who held that arthritis deformans was essentially a disease of debility

Dr. Stewart having briefly replied, the discussion came to a conclusion.

The section subsequently took up the hearing of short papers. Dr. Tyson (Philadelphia) read a paper on "Note on the proper use of Terms to denote Myocardial Changes." Dr. Fussell (Philadelphia) read a paper on "Two cases of Hrmophilia." Dr. McConnell read a paper on "Pyopericardium following Pleuro-pneumonia, Pericardiotomy, Rucovery." Other business followed and the sectiun adjourned.

\section{B. SURGERY.}

President : Christopher Heath, F.R.C.S., London.

Hon. Secs : R. C. Kirkpatrick, M.D., Montreal ; Thomas Walker, M.D., St. John, N.B. ; Jordan Lloyd, F.R.C.S., Birmingham.

The President in his opening remarks, after gracefully alluding to the honour he felt at being asked to preside on such an occasion, referred to the special subjects selected for debate in this section, viz., (1) Appendicitis and its surgical treatment, and (2) the treatment of cancer of the rectum, with special reference to the high operation. Nothing was more remarkable than the recent progress of abdominal surgery, for neither of these subjects were treated by surgeons twelve years ago, when he (Mr. Heath) was engaged in editing a Dictionary of Practical Surgery. He referred to other changes in practice, and adversely commented on the prevalent sacrifice of time to scientific study at the expense of clinical work.

Dr. G. E. Armstrong, of Montreal, read a paper on "Appendicitis and its Treatment." His remarks were based on 517 cases collected from the Montreal General, Royal Victoria and Western Hospitals. The cases of this disease, he said, tended to increase rapidly during the first three decades of life; but to diminish in frequency after 30 years of age. As to sex there were nearly two males to one female. A number of specimens in formalin were shown, prepared by Dr. Wyatt Johnston. Many cases start from abrasions and facal ulcers, causing loss of epithelium and thus preparing a passage for the bacterial invasion. As a result of ulceration and healing a narrow ing of chnal was produced. Freces, pus, etc., might become pent up by the stricture and later cause perforation. Obliteration of canal might occur if contraction began at the distal end of appendix. Fifty-nine of the 389 cases reported upon contained fecal concretions. As regards treatment operation was strongly advocated as the only means of obtaining a good result with certainty. In the Montreal General Hospital from 1858-1800 there occurred $15 \tilde{y}$ cases of peritonitis and perityphlitis. Of these 37 died a mortality of 23.8 per cent. Since 1890,517 cases had beenadmitted to the three hospitals, with mortality of 12.8 per cent., the mortality being lowered by about half. The results are still improving. Eighty-four cases of operation during the interval were reported without a single death. The cause of death generally is due to abscess formation and its sequelæe and general septic peritonitis. In operating on cases with abscess formation the author advised the complete removal of sac wall, which could be done without infecting the general peritoneal cavity. Thus secondary abscesses would not be overlooked and the spread of infection to the liver through the portal veins be obviated. Fifteen cases of fæcal fistula followed operation. Four died, eight healed spontaneously, one healed after operation, and in two the result was not stated. The author reported 29 cases, with one death treated at the General Hospital since October 1st, 1896. He advised free drainage with large rubber tubes, one in each loin and one dipping down into pelvis.

Dr. Ward Cousins (Southsea) agreed with Dr. Armstrong's conclusions. Appendicitis required careful watching. Statistics were no help in deciding upon operation. Certain cases required dieting and rest only. The great question was as to the adrisability of operation and the time of performing it.

Prof. Ball (Dublin) divided appendicitis into four classes, viz. : 1. Those developing suddenly with peritonitis. 2 . Those in which abscess formation has taken place. 3. Those repeated attacks which render a man's life miserable. 4. Those whose symptoms are such that there is a grave doubt as to the extent of the disease. In the first two peration was imperative. In the third operation should take place during the interval of the attacks. In the fourth there was douht as to when the operation should be performed.

Mr. Jordan Lloyd (Birmingham) thought the disease appendicitis meant a disease confined within the appendix. He thought that the locality of the abscess depended entirely on the locality in which the appendix swings. Sir. Wm. Hingston (Montreal) employed a conservative mode of treatment in these cases. He could cite 27 cases where he had refused to operate and where the patients subsequently recovered. He thought that in the treat ment of this disease the physician and surgeon should go hand in hand.

Dr. Vander Veer (Albany) concurred in the statements of Mr. Lloyd in regard to the locality of the appendicular abscess, and advocated early operation.

Dr. Alex. Hugh Ferguson (Chicago) treated appendicitis as a purely surgical affection. Hedid not believe in opera tion during the acme of the inflammation; better shortly before or after the acme. He believed in operating in clearly defined cases of appendicitis. He had used intravenous saline infusion in chronic septic cases.

Dr. Gordon (Portland) strongly urged the medical treat ment of appendicitis at the beginning of an attack. He gave large doses of a saturated saline solution and in some cases also gave a saline enema. This often relieved the pain in a very short time.

The President said that Dr. Gordon's views corresponded with his own. He had frequently relieved the pain very materially by the application of belladonnd over the appendix or the addition of a hot linseed poultice over this. The patient should be kept in bed and dieted as strictly as in a case of typhoid.

Dr. Armstrong, in reply, said that he had never succeeded with gauze as a means of draining: he frequently found pus pent up behind it. Gauze would only drain the serum. The application of hot poultices or ice he thought of value in the early stages.

Dr. A. F. Garrow (Montreal) read a paper on "A case of Umbilical aud Ventral Hernia in the same patient." He alluded to the rarity of the condition, only one similar case being reported within the past twelve years. In the case under consideration the contents of the supra-umbilical pro trusion consisted of large and small intestine, crecum with appendix and omentum which was adherent and reduced with difficulty. The umbilical hernia was small, sausageshaped, non-adherent, readily reducible.

Dr. Alexis Thomson (Edinburgh) then read a paper on "Stricture of the Intestines as a sequel of Strangulated Hernia." The case was that of a man aged 29. A loop of bowel had become strangulated, causing a local peritonitis, the constriction being at the internal ring. The patient did well for three weeks, when symptoms of obstruction occurred. It was found necessary to make an artificial anus in the upper portion of bowel until such time as the upper distended portion assumed somewhat the same size as the lower portion, when the ends were united with the Murphy button.

Dr. Marcy (Boston) read a paper on the "Suturing of Wounds."

Dr. Langley Browne read a paper on "Traumatic Aneurism of the Internal Maxillary Artery, treated by Ligature of the Common Carotid." In this case a man aged 32 years was kicked by a horse on March 12, 1897. On April 9th pus was evacuated from an abscess on the neck at seat of injury. Shortly after this a distinct swelling (pulsating) behind the jaw was made out. The common carotid was tied in this case on April 26th. The patient was discharged cured on May 24 th.

Dr. Theo. McGraw (Detroit) read a paper on "Invagination of the Crecum and Vermiform Appendix." In this case a diagnosis could not be made, the only distinguish ing feature being the severe recurrent attacks of abdominal pain (relieved only after administration of morph. gr. $\frac{3}{4}$ ) unaccompanied by fever or any digestive disturbance.

\section{c. PUBLIC MEDICINE}

President: E. P. Lachapelle, M.D., Montreal.

Hon. Secs.: Wyatt Johnston, M.D., Montreal ; E. Pelletier, M.D., Montreai ; Harvey Littlejohn, M.B., C.M., Edinburgh.

The President opened the proceedings of the Section with an address on the Progress of Sanitation in Canada- 
commencing with an interesting account of hygienic measures under the French regime, one of the first measures being the promulgation of an ordinance by Louis XIV., establishing for the civil state a system of registration, still in force in the Province of Quebec. Regulations concerning the food supply were enforced in Quebec a few years later,-measures being taken to secure that the inhabitants were provided with good meat. Passing to sanitation under the British rule, he pointed out that for some years nothing was done, but in 1795 measures of inspection and quarantine were adopted to prevent the importation into the colony of typhus fever, then raging in Ireland. Government medical vaccinators were appointed from 1815 to 1821 , and vaccination encouraged but not made compulsory. The appearance of cholera in 1822 led to special measures being undertaken, and in 1849 on another invasion of the disease a statutary law was enforced which was utilised in 1855 during the epidemic of variole. With the advent of the Confederation in 1867 , sanitary legislation became more systematised, and Dr. Lachapelle passed in review the various measures which then and since have been enforced under the heads of Federal Sanitation and Provincial Sanitation, and shewed that with regard to sanitary matters, Canada is advancing rapidly, since the formation in 1880 of the Provincial Board of Health.

Several papers were then read referring to mandatory measures in dealing with measles, whooping cough, tuberculosis and leprosy. The readers were Dr. P. H. Bryce, Secretary of the Provincial Board of Health, Ontario ; Dr. C. O. Probst, Secretary State Board of Health, Ohio; and Dr. H. Handford, of Nottingham, England.

Dr. Bryce's paper was a lengthy one. He discussed measles, scarlet fever, whooping cough and tuberculosis. After citing statistics, he advocated the closing of schools when scarlet fever and measles were prevalent in epidemic form. The use of notification cards and isolation were dwelt on at lengtb. He was in favour of compulsory measures, and the early removal to hospital in cases of measles and scarlet fever. He spoke of leprosy in the United States of America as having caused 16 deaths. In Canada it did not seem to have any significance. He knew of and referred to the Leper Asylum at Tracadie, and said that if it was contagious, segregation was necessary. With regard to isolation in tuberculosis, the danger was from the bacilli : they might live for a year. Houses which had been occupied by consumptives should be disinfected. Tuberculosis was a contagious disease and great care was necessary. 'The sputum should be disinfected.

Dr. Probst went over much of the same ground. For men in the American Navy he recommended early recognition of the disease, and special hospitals. Any plan for the prevention of tuberculosis must consider the liability of animals to infection and the question of infected milk. Regarding the care of herds of cows, the healthy animals should be separated from the unhealthy. Calves born of unhealthy cows should be separated and fed on healthy milk. The bad ventilation of stables was responsible for much of the disease among cattle.

Dr. Handford, of Nottingham, in his opening remarks said that there was no want of legislation in England regarding such matters, but they did want a Minister of Public Health. Many advances must be made in hygiene and public health. Regarding mandatory measures in England compulsion had completely failed. The people must be educated, their confidence must be gained. The education of the wealthy in such matters was as necessary as the education of the poor. In Nottingham no case of scarlet fever had ever been removed to a public hospital on a magistrate's order. As a result of eight or ten years' observation 90 per cent. of the cases of scarlet fever were now voluntarily sent to the hospitals in his district.

Dr. Oldright, of Toronto, spoke regarding sanitary regulations and compulsion. Educational measures were necessary. He dwelt on the value of education and persuasion. In England measles was a more severe disease than in this country, while there whooping cough was less severe than in Canada. Children with whooping cough vere seen in street cars and on steamboats, their parents paying but little attention to it. Nothing, he remarked, had been said about consumptives at health resorts. The rooms occupied by such patients were not disinfected, and hence arose a great source of danger-such as when persons travelling infect sleeping cars, their blankets, and their rugs.

Dr. Wolfred Nelson, of New York, formerly of Montreal and Panama, referred briefly to his experience of leprosy in the Isthmus of Panama. Speaking generally he deemed it non-contagious and referred to the 1893 PanAmerican Medical Congress in Washington, where the matter was discussed fully when the late Dr. Beaven Rake, Dr. Liceaga, of Mexico, and others quite familiar with leprosy were present. There he (Dr. Nelson) had asked the Section on climatology demography and quarantine not to countenance any legislation tending to hamper an unfortunate class of sufferers, in no wise dangerous to the public; out of fifty delegates then assembled, forty. eight voted for his motion.

Dr. Carr, of England, suggested that as the Section seemed to be in acrord in essentials, it might be well to point out the differences. All agreed on the advantages of isolating cases of scarlet fever and of phthisis. Ile deemed ventilation very necessary.

Sir James Grant, of Ottawa, referred to scarlet fever in Ottaua in the days before they had drainage there, and cited a case where scarlatina maligna killed four in one family in two days. He traced it to a damp cellar and defective drainage. He dwelt at length on scarlatinal in fection and glandular absorption.

\section{OBSTETRICS AND GYNACOLOGY.}

President: William Japp Sinclair, M.D., Mancbester. Hon. Secs.: D. J. Erans, M.D., Montreal ; W. Burnett, M.D., Montreal ; Arthur E. Giles, M.D., London.

The Section was opened by Dr. William Gardner, of Montreal, who introduced the President, Dr. W. Japp Sinclair, of Manchester.

Dr. Henrotin, of Chicago, read a paper on "The Oper. ation of Choice in the Surgical 'l'reatment of Septic Pelvic Diseases, with special reference to the early vaginal incicision." The discussion on this paper was postponed till Thursday.

Dr. J. Algernon 'Temple, of Toronto, opened a discussion on "Hyperemesis Gravidarum." He said he would confine himself to the question of otiology, leaving the diagnosis and treatment of it to subsequent speakers. In looking over the literature he had found very little that was defi. nite: almost every writer who reported a fatal case ad. vanced his own view's as to the possible cause of it; but it was only in those fatal cases where a post-mortem had been made that statements of anf value were found; the rest was merely speculative. Primigravide were the principal sufferers; and it was much more fatal than some writers would lead them to believe. The ordinary morning sickness of pregnancy he regarded as physiological and not dependent on any pathological condition; but in the pernicious form it was invariably accompanied by some pathological condition.

The majority of theories ascribed the pathogenesis to reflex phenomena originating in conditions present in connection with the pregnant uterus; but the way in which uterine conditions gave origin to peripheral irritation had been variously explained. Graily Hewitt laid great stress on flexions and versions in the growing uterus. J. H. Bennett emphasized the importance of infiammatory conditions of the cervix. Howitz drew attention to the pregnancy of metritis and cellulitis in these cases. J. Veit, in three cases where he had to terminate pregnancy, found inflammatory conditions of the decidua vera and serotina. Ebell held the same view and regarded the relations as proren. Bretonneau suggested that the peripheral irritation orginated in the stretching of the fibres of the growing uterus, and the pressure on the nerves occasioned thereby. Copeman and Gill Wylie also adopted this explanation, whilst $\mathbf{H}$. H. Grandin suggested ovarian irritation as a cause. Others explained it as due to a nervous temperament and hysteria; or to disease of the intestinal tract Haden's toxic theory had many adherents, and Tumas had recently located a vomiting centre in the medulla, in close relation to the centre which presides over the generative organs. They were all aware that pregnancy was accompanied by changes in almost every tiscue of the body, as well as a hydramie condition of the blood and a generally exalted excitability of the nerrous system, an his own experience led him to a similar con clusion

Dr. Arthur Giles, of London, England, said that some years ago it occurred to him that some light on the subject of hyperemesis gravidarum might be derived from the examination of the causes of the ordinary vomiting of pregnancy. For this purpose he analysed the records of 300 cases in the General-Lying-in-Hospital in London, the results being recorded in the Obstetrical Transactions for 1893. He found that in 33 per cent. of the cases there was no vomiting at all during pregnancy, consequently he could not record the ordinary vomiting of pregnance as physiological. Further, in 50 per cent there was no romit. ing during the first three months. Vomiting during the 